\title{
Process Optimization for the Biopolishing of Jute Fibers with Cellulases from Aspergillus Nidulans AJ SU04
}

\author{
S. Anuradha Jabasingh and C. Valli Nachiyar
}

\begin{abstract}
The enzyme cellulase of higher activity $(49.82 \mathrm{U} / \mathrm{ml})$ from Aspergillus nidulans AJ SU04 was applied for the biopolishing of jute fibers in this study. Application of cellulase in fabric biofinishing is investigated by treating the jute fibers with partially purified cellulase and studying the enhancement of fiber brightness, smoothness and weight loss. The biofinishing conditions including treatment time, fiber to enzyme ratio (concentration), agitation rate and temperature are optimized for a smooth fiber surface. The results of the scanning electron microscope (SEM) analysis, X-ray diffraction (XRD) and Fourier transform infrared spectroscopy (FTIR) favored maximum surface finishing. The optimized conditions for the biopolishing of jute fibers were found to be $45^{\circ} \mathrm{C}$, PH 5.0 and $17 \mathrm{~h}$ of the treatment. The optimum jute fiber concentration was found to be $16 \%(\mathrm{w} / \mathrm{v})$.
\end{abstract}

Index Terms - Cellulase, aspergillus nidulans, jute fiber, biofinishing.

\section{INTRODUCTION}

In the textile industry, there is a need for novel cellulases that are active at neutral and alkaline $\mathrm{pH}$ values, have short reacting time, do not compromise the strength of fabric, and have good finishing properties [1]. The ability of certain fungal species to decompose the cellulosic biomass into glucose, which in turn can be converted into valuable chemicals, has made cellulases as one of the most important commodity [2]. Cellulases are inducible enzymes which are synthesized by microorganisms during their growth on cellulosic materials [3]. Cellulase production in fungi is found to be extra cellular and has three components such as endoglucanase (endo-1, 4- $\beta$-D-glucanase, EC 3.2.1.4), exoglucanase (exo-1, 4- $\beta$-D-glucanase, EC 3.2.1.91) and $\beta$ glucosidases (1, 4- $\beta$-D-glucosidase, EC 3.2.1.21). The main applications of these enzymes are in textile, paper and pulp, food, animal feed, fuel and chemical industry [3].

Cellulase treatment of fibers is an environmental friendly way of improving the property of fabrics, their desirable appearance and soft handle [4], [5]. Jute is a ligno-cellulosic fibre that is partially fibre and partially wood. India is the world's largest jute growing country with its cultivation localized in the states of West Bengal, Orissa, Bihar, Assam, Meghalaya, Tripura and Andhra Pradesh. The treatment of Jute with cellulase reduces brittleness and stiffness and promotes its affinity to readily accept dyes. Success of jute

Manuscript received September 27, 2011; revised December 10, 2011.

S. Anuradha Jabasingh is with the Department of Chemical Engineering, Sathyabama University, Tamilnadu 600119, India (Corresponding author Phone: +91 (044) 42647447; fax: +91 (044) 24501065; e-mail: anu3480@yahoo.com).

C. Valli Nachiyar is with the Department of Biotechnology, Sathyabama University, Tamilnadu 600119, India. (e-mail: vnachiyar@gmail.com). bio-finishing is influenced by $\mathrm{PH}$, temperature, enzyme-substrate ration, treatment time and mechanical action [6], [7]. Endo-riched cellulase resulted in reduced strength loss [8]. Commercial cellulases for bio-finishing originate from Trichoderma reesei and Humicola insolens [9]-[11]. A study was previously made for jute bio-finishing using cellulase from Phanerochaete chrysosporium and Ceriporiopsis sub vermispora under specific treatment conditions on the physical characteristics of jute fibers [12]. The Aspergillus nidulans strain, isolated in our laboratory was seen to secrete endoglucanases maximally [13]. The crude cellulase extract obtained was partially characterized and some studies were made aiming at its possible application in jute fiber treatment [14].

\section{MATERIALS AND METHODS}

\section{A. Enzyme and Fiber}

Aspergillus nidulans AJ SU04 was used in the production of cellulase [8]. The clarified crude enzyme preparation was used in enzyme assays and jute fiber treatment. Jute fibers were obtained from sorbead mills, Gujarat.

\section{B. Enzyme Treatment on Jute Fibers}

The fibers were cleaned by hand to remove impurities, such as seed fragments and debris. Fibers were then boiled in water at $100^{\circ} \mathrm{C}$ for $30 \mathrm{~min}$. After removal from the boiling water, the fibers were rinsed with deionized water and air-dried. The jute fibers were then soaked thoroughly in 100 $\mathrm{mL}$ enzyme preparation $(49.82 \mathrm{U} / \mathrm{mL})$ and incubated at $50^{\circ} \mathrm{C}$ for 24h [4]. The enzyme was completely inactivated after the treatment by boiling the fibers in water for $5 \mathrm{~min}$. The enzyme treated samples were then washed thoroughly in running tap water followed by distilled water. The treated materials were air dried. Control samples consisted of fibers treated in an identical manner but without enzymes. These treated jute fibers were tested for their brightness, smoothness and weight loss. Fiber brightness is defined by the percentage of light reflected. Smoothness is a surface characteristic relating to the measure of surface irregularities and is measured in terms of ETR (Estimated test result) values. It is defined as the time required for $10 \mathrm{~cm}^{3}$ of air, under a vacuum of $50.66 \mathrm{kPa}$ to pass between the surface of the fiber matrix and a polished $10 \mathrm{~cm}^{2}$ glass discs, held under a pressure of $1 \mathrm{~kg} / \mathrm{cm}^{2}$. The bio-finishing conditions including treatment time, fiber to enzyme ratio (concentration), agitation rate and temperature are optimized for a smooth fiber surface.

\section{Analytical Techniques}

Assay for cellulases and reducing sugar were carried out 
according to IUPAC recommendation [13], [15], [16]. Glucose in the culture supernatant was analyzed by using UV Visible spectrophotometer (Hitachi Model: 100-40 Spectrophotometer) at $540 \mathrm{~nm}$. The jute fiber was soaked thoroughly in $100 \mathrm{ml}$ enzyme preparation $(49.82 \mathrm{U} / \mathrm{ml})$ and incubated at $50^{\circ} \mathrm{C}$ for $24 \mathrm{~h}$. Control samples consisted of fibers treated in an identical manner but without enzymes. Treated fibers were tested for their brightness, smoothness and weight loss. X-ray diffraction analysis was carried out to examine the structural properties of jute samples (Miniflex Model, Rigaku, Japan). Surface morphology was analyzed using Scanning electron microscope (Philips XL30 SEM). FTIR spectrum was recorded in the region of $400-4000 \mathrm{~cm}^{-1}$ (Nicolet 20DXB spectrometer). Brightness index was measured on (Photovolt reflection meter: model 670), provided with tristimulus filters of known reflectance value (93\%) with reference to magnesium oxide as $100 \%$ brightness value. Microprocesser controlled smoothness tester (Automatic bekk: model 58-05-00) is used for the determination of smoothness of the fiber matrix.

\section{RESULTS AND DISCUSSION}

\section{A. Biofinishing Experiments on Jute Fiber}

The fibers were cleaned to remove impurities and boiled in water at $100^{\circ} \mathrm{C}$ for $30 \mathrm{~min}$. After removal from the boiling water, the fibers were rinsed with deionized water and air-dried.
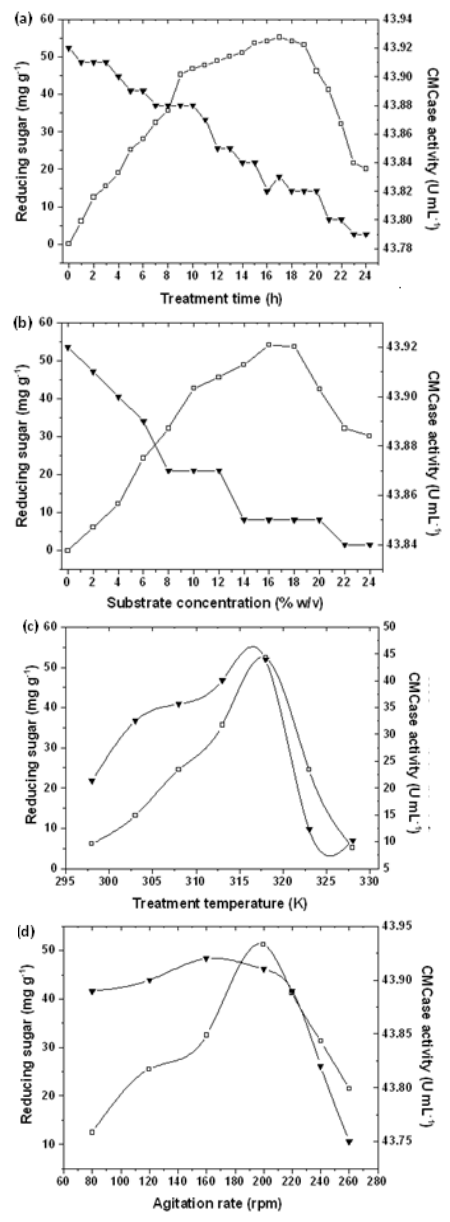

Fig. 1. Effect of (a) time, (b) substrate concentration (c) temperature and (d) agitation rate on the yield of reducing sugars $(\square)$ and CMCase $(\boldsymbol{\nabla})$ during the biofinishing of Jute fibers by cellulase from Aspergillus nidulans
The treatment of the jute fibers with crude CMCase resulted in an increase in the yield of reducing sugars from $2^{\text {nd }} \mathrm{h}$ till the $17 \mathrm{th} \mathrm{h}$ after which the release of reducing sugars decreased. The results of the effect of enzymatic hydrolysis on jute fiber were studied at substrate concentration from $2 \%$ to $24 \%(\mathrm{w} / \mathrm{v})$.
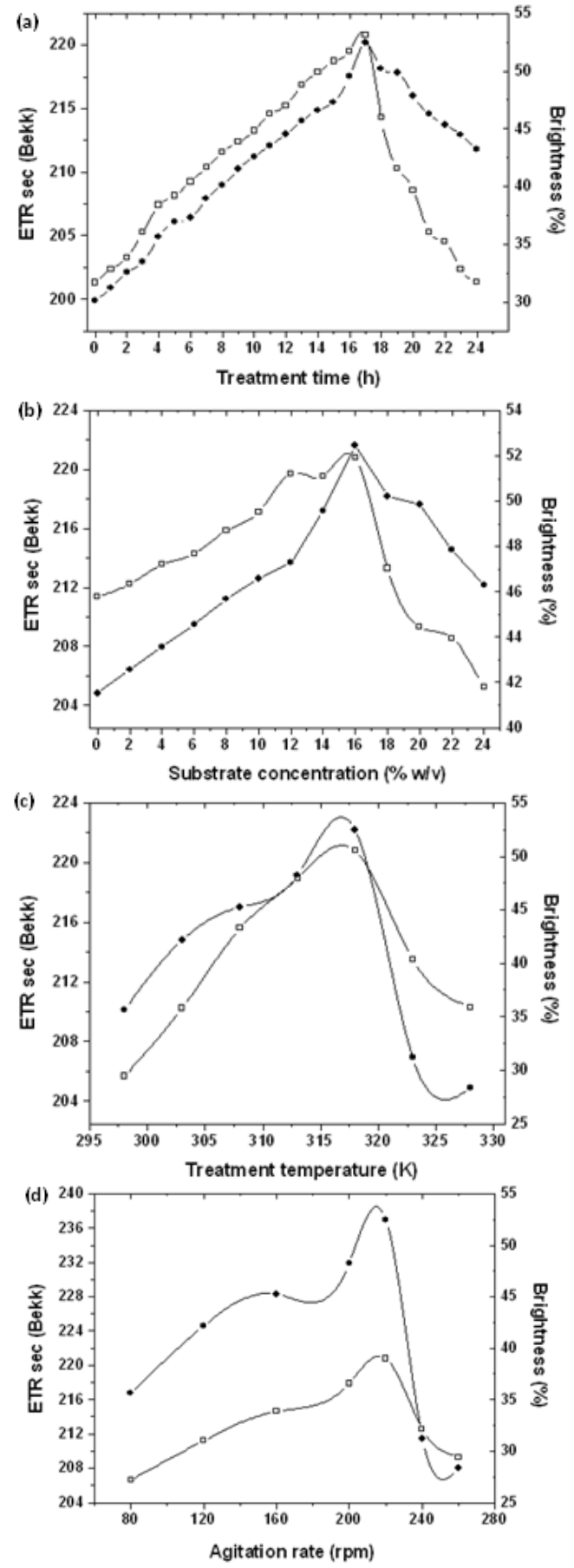

Fig. 2. Effect of (a) time, (b) substrate concentration, (c) temperature and (d) agitation rate on smoothness $(\square)$ and brightness \% (•) of Jute fibers

Minimum loss in weight, maximum brightness and maximum surface smoothness were achieved at substrate concentration of $16 \%$ jute fiber. The cellulase treatment of jute fibre was carried out between $25^{\circ} \mathrm{C}(298 \mathrm{~K})$ and $55^{\circ} \mathrm{C}$ $(328 \mathrm{~K})$. The temperature of $45^{\circ} \mathrm{C}$ was found to be optimum for the treatment of jute fibers with the cellulase. The agitation rate of $200 \mathrm{rpm}$ was found to be optimum for the treatment of jute fibers with the cellulase obtained from Aspergillus nidulans AJ SU04 (Fig. 1a-d). 


\section{B. Effect of Cellulase Treatment on Smoothness and Brightness of Jute Fibers}

The enzyme-treated jute fibers were tested for their ETR values in the test for smoothness. The ETR values observed after the smoothness test was $230.2 \mathrm{sec}$ (Bekk) at $50.66 \mathrm{kPa}$. At $48.00 \mathrm{kPa}$, the ETR value for $16 \%$ jute fiber treated for 17 $\mathrm{h}$ at $45^{\circ} \mathrm{C}$ was observed to be $220.78 \mathrm{sec}$ (Bekk) confirming the smoothness of the enzyme treated fiber matrix. In the test for brightness and whiteness, the voltmeter of photovolt reflection meter was set according to manual and 30 readings were taken randomly. The averages were considered as appropriate brightness. The brightness property of jute fiber was enhanced to some extent by the enzymatic treatment. The maximum brightness of jute fiber was recorded as $52.46 \%$ for $16 \%(\mathrm{w} / \mathrm{v})$ jute fiber treated for $17 \mathrm{~h}$ at $45^{\circ} \mathrm{C}$. Result indicates bleaching effect of crude enzyme preparation from Aspergillus nidulans AJ SU04 on jute fibers. The ETR values and brightness values (\%) upon various treatment times $(2-24 \mathrm{~h})$, substrate concentrations $(2-24 \%$ w/v), temperatures $25^{\circ} \mathrm{C}(298 \mathrm{~K})-55^{\circ} \mathrm{C}(328 \mathrm{~K})$ and agitation rate (80-260 rpm) were shown in Fig. 2a-d.

\section{Scanning Electron Microscopic Images of Jute Fibers}

The change in the morphology of the fiber mat during the treatment shows the development of smoothened surface possibly due to the accumulation of the enzyme in the fiber matrix and subsequent removal of the unwanted micro fibrils. After 17th $\mathrm{h}$ of operation, a linear reduction in weight change was seen possibly due to the roughening of the fiber surface by the formation of cavities and stripping off of the fiber wall. The increase in surface roughness, however, is relatively small and is found to be localized and very superficial, as expected from the long treatment time.

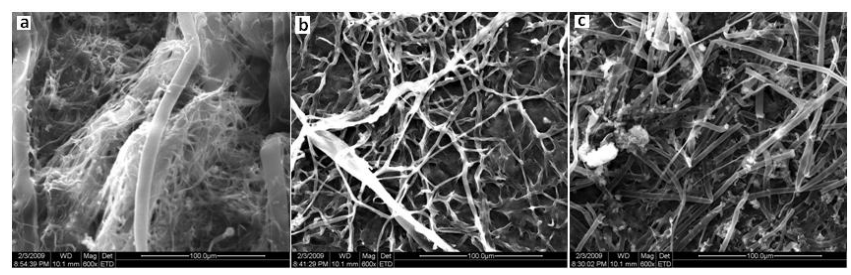

Fig. 3. SEM micrographs of (a) untreated jute fibers $(100 \mu \mathrm{m})$ (b) jute fibers treated for $15 \mathrm{~h}, 16 \%(\mathrm{w} / \mathrm{v}), 45^{\circ} \mathrm{C}, \mathrm{pH} 5.0,49.82 \mathrm{U} / \mathrm{ml}$ cellulase $(100 \mu \mathrm{m})(\mathrm{c})$ jute fibers treated for $17 \mathrm{~h}, 16 \%(\mathrm{w} / \mathrm{v}), 45^{\circ} \mathrm{C}, \mathrm{pH} 5.0,49.82 \mathrm{U} / \mathrm{ml}$ cellulase $(100 \mu \mathrm{m})$.

SEM images provide a qualitative confirmation of these results. At the 17 th $\mathrm{h}$ of the treatment (Fig. 3a-c), more peculiar surface features appear. Surfaces become more regular and form a more continuous cover of the fiber surface. Large regions can be seen where small fibrils and platelet-like structures protrude from the surface. Additionally, large localized deposits are found, exhibiting cracks [17]. These cracks can be expected to be formed in these large deposits due to shrinking during drying of the treated fibers. From these SEM images, one can expect the cellulase - fiber interactions to be governed largely by mechanical interlocking and Van der Waals forces. Representation of the possible mechanism of enzymatic finishing of jute fiber is given by a schematic representation (Fig. 4).

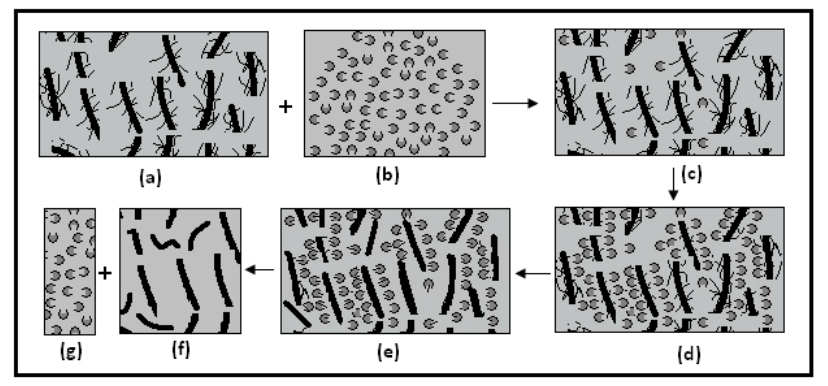

Fig. 4. Possible mechanism of the cellulase bio-finishing of Jute fiber: $(\rightarrow)$ indicates steps.

The Fig. 4 represents the following: (a) Jute fibers with protruding micro fibrils; (b) Addition of cellulase to act upon microfibrils; (c) Cellulase action on microfibrils; (d) Establishment of lock and key mechanism by endoglucanase component with protruding micro fibrils; (e) Action of endoglucanase on protruding fibers and hydrolysis of protruding micro fibrils; (f) Completely de-microfibrilled and biofinished Jute fiber and ( $\mathrm{g}$ ) cellulase after the biofinishing action.

Endoglucanase acts on the amorphous region of the cellulose, forming the protruding hairs and loosens it. The mechanical action of stirring during the treatment in turn removes the loosened fibers to give a final finished product. The weight loss less than $0.5 \%$ during the treatment may be only due to the removal of surface fibrils, water extractable material, and other impurities from the jute fiber. Maximum weight loss was achieved when the jute fiber to enzyme ratio was $15 \%$, possibly due to the complete removal of the microfibrils.

\section{Jute Fiber Weight Loss on Bio-Finishing}

Minimum weight loss was seen at $50 \%$ of the jute fiber to enzyme ratio, probably due to the diffusional limitations of the enzyme at higher ratios. These results showing negligible weight loss of the fiber after bio-finishing is shown in TABLE I.

\begin{tabular}{cc}
\hline TABLE I: WEIGHT LOSS OF JUTE FIBER \\
\hline $\begin{array}{c}\text { Jute fiber to } \\
\text { cellulase conc.(w/v) }\end{array}$ & $\begin{array}{c}\text { \% weight loss } \\
\text { of Jute fiber }\end{array}$ \\
\hline 5 & 0.21 \\
\hline 6 & 0.21 \\
\hline 7 & 0.22 \\
\hline 8 & 0.23 \\
\hline 9 & 0.24 \\
\hline 10 & 0.25 \\
\hline 15 & 0.26 \\
\hline 20 & 0.24 \\
\hline 25 & 0.23 \\
\hline 30 & 0.22 \\
\hline 35 & 0.18 \\
\hline 40 & 0.16 \\
\hline 45 & 0.15 \\
\hline 50 & 0.14
\end{tabular}

Trichoderma cellulase with high FPase $(50 \mathrm{U} / \mathrm{mL})$ showed aggressive action on cotton. In our study, enzyme treatment with Aspergillus nidulans cellulase increased dimensional stability and softness of jute fibers. 


\section{E. X-ray Diffraction Pattern of Jute Fibers}

Fig. 5 shows an XRD pattern of jute samples with $2 \theta$ verses intensity having several peaks of cellulose indicating random orientation for the crystalline nature.

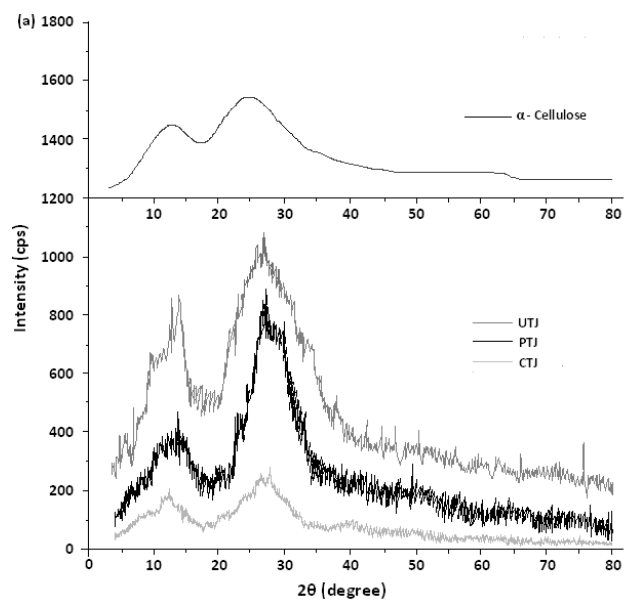

Fig. 5. XRD pattern of $\alpha$-cellulose, untreated jute (UTJ), pretreated jute (PTJ) and cellulase treated jute (CTJ) fibers.

Measured interplanar distances agreed with the values reported for cellulose in the literature [15]. The XRD of $\alpha-$ cellulose, untreated jute (UTJ), pretreated jute (PTJ) and cellulase treated jute (CTJ) prove decline in the crystallinity of samples in the order of $\alpha$ - cellulose standard, UTJ, PTJ and CTJ.

\section{F. FTIR Spectra of Jute Fibers}

The Fourier transform infrared spectroscopy shows peaks corresponding to cellulose [18],[19] and lignin [20]. The lignocellulosic composition of the jute could be identified from the presence of peak between $1600 \mathrm{~cm}^{-1}$ and $1000 \mathrm{~cm}^{-1}$. The FTIR spectra of the jute samples were shown in Fig. 6. Band intensities of lignin peaks were predominant in the untreated jute $1238 \mathrm{~cm}^{-1}$. This region is associated to carbonyl groups including ketones, esters and aldehydes which are cellulose related groups.

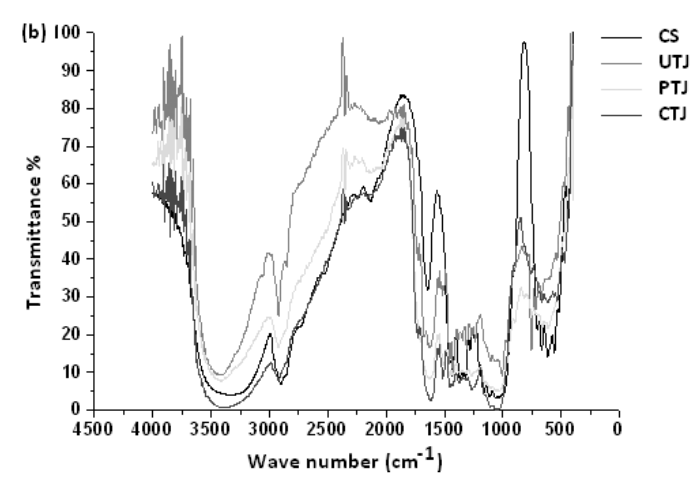

Fig. 6. FTIR spectra of $\alpha$-cellulose, untreated jute (UTJ), pretreated jute (PTJ) and cellulase treated jute (CTJ) fibers.

The FTIR band at $2900 \mathrm{~cm}^{-1}$, assigned to C-H stretching vibration is a measure of general organic material content of the jute. The peak at $1735 \mathrm{~cm}^{-1}$ attributed to $\mathrm{C}=\mathrm{O}$ stretching of the carbonyl and acetyl groups in the 4-O-methyl-glucanoacetyl xylan component of hemicellulose in the jute, disappears on pretreatment and more on hydrolysis. Total disappearance of $1650 \mathrm{~cm}^{-1}$ and
$1540 \mathrm{~cm}^{-1}$, attributed to the primary and secondary amides in the solid structure of jute on hydrolysis could be inferred from the FTIR spectra. The band $1508 \mathrm{~cm}^{-1}$ indicating the presence of aromatic rings of lignin decreases more in intensity on hydrolysis than on pretreatment. $1433 \mathrm{~cm}^{-1}$ band assigned to $\mathrm{CH}_{2}$ symmetrical deformation was absent in untreated jute but appears in the jute after hydrolysis indicating the change in environment of $\mathrm{C}_{6}$ carbon atom due to the formation of hydrogen involving atom $\mathrm{O}_{6}$.

The peak at $1735 \mathrm{~cm}^{-1}$ attributed to $\mathrm{C}=\mathrm{O}$ stretching of the carbonyl and acetyl groups in the 4-O-methyl-glucanoacetyl xylan component of hemicellulose in the jute, disappears on pretreatment and more on hydrolysis. Total disappearance of $1650 \mathrm{~cm}^{-1}$ and $1540 \mathrm{~cm}^{-1}$, attributed to the primary and secondary amides in the solid structure of jute on hydrolysis could be inferred from the FTIR spectra. The band $1508 \mathrm{~cm}^{-1}$ indicating the presence of aromatic rings of lignin decreases more in intensity on hydrolysis than on pretreatment.1433 $\mathrm{cm}^{-1}$ band assigned to $\mathrm{CH}_{2}$ symmetrical deformation was absent in untreated jute but appears in the jute after hydrolysis indicating the change in environment of $\mathrm{C}_{6}$ carbon atom due to the formation of hydrogen involving atom $\mathrm{O}_{6}$.

\section{CONCLUSION}

The present study demonstrates the magnitude of cellulase produced by Aspergillus nidulans AJ SU04 and its potential for textile finishing processes. Cellulase treatment on $16 \%$ (w/v) jute fiber for $17 \mathrm{~h}$ at $45^{\circ} \mathrm{C}$ showed good bio-finishing effect. Bio-finishing action is expected to be enhanced by the optimization of treatment conditions. A continued multidisciplinary research on the basic and applied aspects of optimization is essential to meet the growing demand for cellulases in textile industries. Aspergillus nidulans AJ SU04 cellulase, rich in endoglucanase appears to be exceptional for bio-finishing operations more preferred for textile application. Additional improvements can be expected by considering the wetting properties, pore volume distribution and strength of fibers after the treatment.

\section{REFERENCES}

[1] R. Anish, M. S. Rahman, and M. Rao, “Application of Cellulases from an alkalothermophilic thermomonospora $s p$. in biopolishing of denims," Biotechnol Bioengg. Vol. 96, no. 1, pp. 48-56, 2007.

[2] J. A. Breznak and A. Brune, "Role of microorganisms in the digestion of lignocellulose by termites," Ann Rev Entomol. Vol. 9, pp. 453-487, 1994.

[3] M. K. Bhat, "Cellulases and related enzymes in biotechnology," Biotechnol Adv, vol. 18, pp. 355-383, 2000.

[4] H. S. Belghiht, S. Ellouz-Chaabouni, and A. Gargouri, "Biostoning of denims by Penicillium occitanis (Pol6) cellulases," J Biotechnol, vol. 89, pp. 257- 262, 2001.

[5] J. Liu, E. Otto, N. Lange, P. Husain, B. Condon, and H. Lund, "Selecting cellulases for bio-polishing based on enzyme selectivity and process conditions," Text Chem Col Am Dyes Rep, vol. 32, no. 5, pp. 30-36, 2000.

[6] A. Cavaco-Paulo, "Improving dimensional stability of cotton fabric with cellulase enzymes," Tex Res $J$, vol. 71, no. 9, pp. 842-843, 2001.

[7] A. Cavaco-Paulo, L. Almeida, and D. Bishop, "Hydrolysis of cotton cellulose by engineered cellulase from Trichoderma reesei, " Text Res J, vol. 68, no. 4, pp. 273-280, 1998.

[8] S. Anuradha Jabasingh and C. Valli Nachiyar, "Optimization of cellulase production by Aspergillus nidulans: application in the biosoftening of cotton fibers," World J. of Microbiol. Biotechnol. Vol. 27, pp. 85-97, 2011a. 
[9] H. Azevedo, D. Bishop, and A. Cavaco-Paulo, "Effects of agitation level on the adsorption, desorption, and activities on cotton fabric of full length and 63 core domains of EGV (Humicola insolens) and CenA (Cellulomonas fimi)," Enz Microb Technol, vol. 27, pp. 325-329, 2000

[10] L. Heikinheimo, J. Buchert, and A. Miettinen-Oinonen, "Treating denim fabrics with Trichoderma reesei cellulases," Tex Res J, vol.70, no. 11, pp. 969-973, 2000.

[11] J. Pere, A. Puolakka, P. Nousiainen, and J. Buchert, „Action of purified Trichoderma reesei cellulases on cotton fibers and yarn," $J$. of Biotechnol, vol.89, pp. 247-255, 2001.

[12] C. Vigneswaran and J. Jayapriya, "Effect on physical characteristics of jute fibres with cellulase and specific mixed enzyme systems," $J$ Tex Inst., vol.101, no. 6, pp. 506-513, 2010a.

[13] S. Anuradha Jabasingh and C. Valli Nachiyar, "Utilization of pretreated bagasse for the sustainable bioproduction of cellulase by Aspergillus nidulans MTCC344 using Response surface methodology," Ind.crop.prod, vol. 34, pp. 1564-1571, 2011b.

[14] A. Kumar, M. Yoon and Purtell C, "Optimizing the use of cellulase enzymes in finishing cellulosic fabrics," Tex Chem Col, vol. 29, pp. 3742, 1997.

[15] G. L. Miller, "Use of Dinitrosalicylic acid reagent for determination of reducing sugar," Anal. Chem. Vol. 31, pp. 426-428, 1959.

[16] H. Jørgensen, A. Mørkeberg, K. B. R. Krogh, and L. Olsson, "Production of cellulases and hemicellulases by Penicillium species: effect of substrate and evaluation of cellulase adsorption by capillary electrophoresis," Enz. Microbial. Technol. Vol. 36, pp. 42-48, 2005.

[17] J. Jayapriya and C. Vigneswaran, "Process optimization for biosoftening of lignocellulosic fiber with white rot fungi and specific enzymatic systems," J Nat Fiber. Vol. 7, no. 1, pp. 17-33, 2010 b.

[18] Y. Cao and H. Tan, "Effects of cellulose on the modification of cellulose." Carbohyd. Res. Vol. 337, pp. 1291-1296, 2002

[19] Y. Cao and H. Tan, "Structural characterization of cellulose with enzymatic treatment," J. Mol. Str. Vol.705, pp. 189-193, 2004.
[20] J. G. Buta and G. C. Galetti, "FT-IR investigation of lignin components in various agricultural lingo cellulosic by-products," J. Sci. Food Agri. Vol. 49, pp. 37-43, 1989

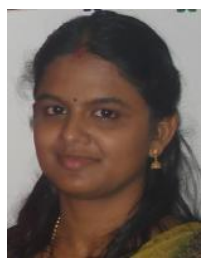

S. Anuradha Jabasingh was born in Chennai, India on $31^{\text {st }}$ August 1980. Currently, she is associated with Sathyabama University, India, as Assistant Professor in the Department of Chemical Engineering. She has obtained her Bachelor of Technology in Chemical Engineering from Sathyabama Engineering College, Madras University, India in 2002 and her Master's in Chemical Engineering from AC College of Technology, Anna University, India in 2004.She was a Gold medalist in her Bachelor degree programme. Her achievements include KAPL award in SBTI 2009, IYSC award in $2^{\text {nd }}$ Indian Youth Science congress 2010, and IET award in SEISCON 2011 for the best paper. She has authored twenty publications in international and national journals. She is a member of many professional bodies including IACSIT, ISCA and IAENG. She is currently pursuing her research in the field of Textile fibre Bio-finishing using enzymes. Her other research interests include sorption studies, composite preparation and catalysis.

C.Valli Nachiyar is Associate Professor and Head of the Department of Biotechnology, Sathyabama University. She has worked on Biodegradation of textile dyes for her Ph.D. work and has over fifteen international publications to her credit. Currently she is guiding research scholars in the field of Microbial Biotechnology and Bioprocess Technology. 